\title{
Consensus statement on definitions and nomenclature for robotic thoracic surgery
}

\author{
Robert Cerfolio, MD, MBA, ${ }^{\mathrm{a}}$ Brian E. Louie, MD, ${ }^{\mathrm{b}}$ Alexander S. Farivar, MD, \\ Mark Onaitis, MD, ${ }^{\mathrm{c}}$ and Bernard J. Park, MD ${ }^{\mathrm{d}}$
}

\section{ABSTRACT}

Objectives: Robotic thoracic operations are increasing, and new robotic systems are imminent. A definition of what constitutes a robotic thoracic operation and a nomenclature to detail the technique used is needed to accurately compare outcomes.

Methods: The American Association of Thoracic Surgeons Guideline Committee appointed an expert consensus writing committee to construct definitions and nomenclature for robotic thoracic surgery. A PubMed search was generated and after vetting and review of the literature a consensus statement was reached.

Results: The proposed definition is: "A robotic thoracic operation is a minimally invasive surgical procedure that does not spread, lift or remove any part of the chest or abdominal wall and is characterized by: the surgeon and the assistant's vision of the operative field is via a monitor only and the patient's tissue is manipulated by robotic instruments that follow a slave like mimic of human hands or thoughts via a computerized system.' In addition, a flexible nomenclature is proposed that should be applicable to current and future robotic systems that details the number of robotic arms used, the types of ports and/or incisions made, the use of insufflation, and the operation performed.

Conclusions: The American Association of Thoracic Surgeons writing committee proposes a definition and nomenclature for robotic thoracic surgery. Definitions are needed to ensure that future studies accurately compare results and outcomes and nomenclatures allow surgeons and scientists from diverse countries and cultures to use the same language to allow accurate communication. (J Thorac Cardiovasc Surg 2017;154:1065-9)

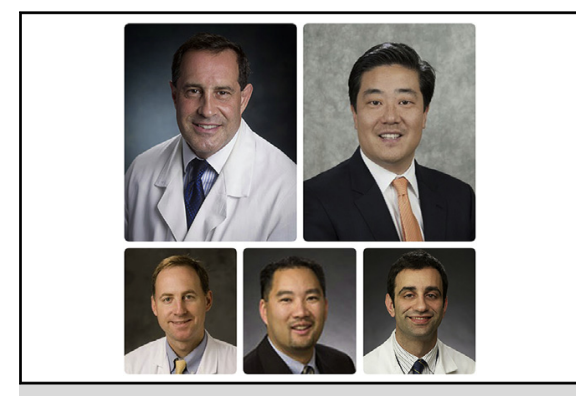

Members of The American Association of Thoracic Surgery Writing Committee.

\section{Central Message}

A consensus statement from The American Association of Thoracic Surgery Guideline Committee on definitions and nomenclature for robotic thoracic surgery is enclosed.

\section{Perspective}

Definitions are needed to ensure that future studies accurately compare results and outcomes and nomenclatures allow surgeons and scientists from diverse countries and cultures to use the same language to allow accurate communication

See Editorial Commentary page 1070.
Minimally invasive surgery has increased in most surgical fields because of the ability to accomplish the same surgical goals through smaller incisions that create less surrounding collateral tissue injury. Robotic surgery is a term used to describe the performance of procedures using small instruments that are mounted on a structure (ie, a robotic platform) and are controlled by the surgeon through a

\footnotetext{
From the ${ }^{a}$ Division of Thoracic Surgery, New York University, New York, NY; ${ }^{\mathrm{b}}$ Division of Thoracic Surgery, Swedish Cancer Institute, Seattle, Wash; ${ }^{\mathrm{c}}$ Division of Thoracic Surgery, Duke University, Durham, NC; and ${ }^{\mathrm{d}}$ Thoracic Service, Department of Surgery, Memorial Sloan Kettering Cancer Center, New York, NY. Received for publication Sept 13, 2016; revisions received Feb 2, 2017; accepted for publication Feb 25, 2017; available ahead of print June 13, 2017

Address for reprints: Robert Cerfolio, MD, MBA, Division of Cardiothoracic

Surgery, New York University, 530 First Ave, Suite 9V, New York, NY 10016

(E-mail: Robert.Cerfolio@nyumc.org).

0022-5223/\$36.00

Copyright (c) 2017 by The American Association for Thoracic Surgery

http://dx.doi.org/10.1016/j.jtcvs.2017.02.081
}

computer-controlled interface. ${ }^{1}$ Robotic surgery, like video-assisted thoracic surgery (VATS), offers a minimally invasive platform to perform complex chest operations and resections and ways to repair/resect a wide variety of complex intrathoracic pathology. The first reported thoracic cases involving robotic technology were performed in the early 2000s, with reports from Europe appearing around $2002^{2,3}$ and from the United States in $2006 .{ }^{4}$

Since these early series, the role and use of robotic systems in general thoracic surgery has expanded rapidly. And, like VATS, as more surgeons began to use the robot, a number of different surgical techniques, incisions, port placements, and approaches were developed. The early VATS literature failed to show the advantage of VATS minimally invasive technique slowing adoption for years. This may have been secondary to the fact that some surgeons were spreading the ribs and labeling it a VATS operation 


\section{Abbreviations and Acronyms \\ $\mathrm{RP}=$ robotic portal \\ VATS $=$ video-assisted thoracic surgery}

because they used a camera to light the operative field. The lack of a definition blurred the outcomes advantages until Swanson and colleagues ${ }^{5}$ helped define what constituted a VATS operation.

Definitions and nomenclature help to ensure a fair comparison of similar approaches. With several new robotic systems close to governmental approval for human use and robotic operations continuing to increase, the objective of this consensus statement is 2-fold. The first is to define what constitutes a robotic thoracic operation and the second is to develop an accepted universal nomenclature that describes the various currently described methods commonly used to perform robotic thoracic surgery. The nomenclature is meant to be flexible enough to be applied to future robotic platforms.

\section{METHODS}

The American Association of Thoracic Surgery Guidelines committee selected a group of authors to form an expert consensus writing committee. Their task was to define and develop a nomenclature to describe the current and possible subsequent types of robotic operations performed in general thoracic surgery. Ideally and in time, all subsequent papers and publications would use one systematic definition and nomenclature.

With the assistance of an experienced medical librarian, we performed 3 literature searches using PubMed searching all languages, for humans, from January 2002 until December 2015. We excluded case reports, literature reviews and general overviews of the topic but included relevant recent meta-analyses. Small case series ( 10 or fewer patients) also were excluded.

For robotic pulmonary lung resection we used the following MeSH headings: (( " "thoracic surgery" OR "pulmonary resection" OR "lung resection" OR "lung surgery" OR "lobectomy" OR "segmentectomy" OR "wedge resection" OR "lung cancer" OR "lung disease" OR "lung diseases") AND robot* OR (("Lung Diseases" [Mesh] OR "Lung Neoplasms"[Mesh] OR "Pneumonectomy”[Mesh]) AND ("Robotics"[Mesh] OR “Robotic Surgical Procedures"[Mesh]))) AND (“2002/01/01”[PDAT]: “3000/12/31”[PDAT]) NOT Review[ptyp]) NOT Case Reports[ptyp].

For robotic mediastinal tumors including thymectomy we used the following MeSH headings: ((c"thymectomy" OR "anterior mediastinal tumors" OR "anterior mediastinal tumour" OR "anterior mediastinal tumours" OR "anterior mediastinal tumor" OR "mediastinal pathology" OR "posterior mediastinal pathology") AND robot* OR (("Thymectomy" [Mesh] OR “Thymus Gland”[Mesh] OR "Thymus Neoplasms”[Mesh] OR "Mediastinal Neoplasms"[Mesh] OR "Mediastinal Diseases"[Mesh] OR "Mediastinum"[Mesh]) AND ("Robotics"[Mesh] OR "Robotic Surgical Procedures"[Mesh])) AND ("2002/01/01"[PDAT] : “3000/12/31" [PDAT])) NOT Review[ptyp]) NOT Case Reports[ptyp].

The articles of each search were acquired and the abstracts reviewed for relevance and duplication. Relevant articles were then reviewed in detail for data elements about the type of robot used, the number of robotic arms used, the location of incisions, the use of an access incision, the use of ports and their size, number, and positions, the conduct of the operation, the method of specimen extraction, the type of pathology and operation performed, lymph node dissection, $\mathrm{CO}_{2}$ insufflation, use of assistants, if rib spreading was used, and the use of an extraction incision including location and length. Articles from the same authors or surgical groups were reviewed, and only one was selected unless there was a significant change in the performance of the operation.

The following definitions were used to categorize the data. An access incision was made at the beginning of the operation through which a bedside assistant could participate in the operation and the pleural space was open to ambient air with or without a wound protector. A completely portal was a nonrobotic trocar through which small specimens such as lymph nodes were removed or instruments such as staplers or suction devices were introduced. An extraction incision was performed at the end of the case for the sole purpose of specimen removal.

\section{RESULTS}

The literature searches identified were 46 papers on robotic pulmonary resection, from which 32 papers were selected and reviewed. A total of 19 were included. There were 30 papers on robotic mediastinal surgery, from which 26 were selected and reviewed. A total of 19 were included, of which 18 reported on surgery in the anterior mediastinum and 2 in the posterior mediastinum.

For robotic pulmonary resection, the dominant approach is a completely portal approach with an extraction incision used to remove the specimen. Three and four robotic arms are used with similar frequency. Access incisions are used occasionally but often in the beginning of one's robotic experience. Table $1^{3,4,6-22}$ lists the articles that met our criteria for pulmonary resection.

Robotic mediastinal surgery was the most consistently performed with the dominant approach using 3 arms in either the right or left thoracic cavity. Extraction incisions were used uniformly and created by extending one of the incisions or occasionally using a lower and wider rib space for larger masses. Table $2^{23-41}$ lists the articles that met our criteria for resection of posterior mediastinal pathology and for anterior mediastinal pathology.

\section{PROPOSED DEFINITIONS OF A ROBOTIC OPERATION}

1. A thoracic operation: "A general thoracic operation is defined as any operative procedure on, or for, lesions or structures found in the thorax, including but not limited to lesions or pathology in the mediastinum, pulmonary parenchyma, chest wall muscles or skeletal structures, diaphragm, or esophagus including the esophagus located in the upper abdomen."

2. A robotic thoracic operation "A robotic thoracic operation is a minimally invasive surgical procedure that does not spread, lift or remove any part of the chest or abdominal wall and is characterized by a surgeon's and assistant's vision of the operative field via a monitor only, while the patient's tissue is principally manipulated by robotic instruments that follow a slave like mimic of human hands or thoughts via a computerized system. It is used for all critical components of the operation." 
TABLE 1. Robotic approaches for pulmonary resection

\begin{tabular}{|c|c|c|c|c|c|c|c|c|c|}
\hline Author & System & Portal & $\begin{array}{c}\text { Assist } \\
\text { incision }\end{array}$ & $\begin{array}{c}\text { Length of } \\
\text { incision }\end{array}$ & No. arms & $\begin{array}{l}\text { Extract } \\
\text { incision }\end{array}$ & Site & $\begin{array}{l}\text { Bag or wound } \\
\text { protector }\end{array}$ & $\mathrm{CO}_{2}$ \\
\hline Rinieri and colleagues $^{6}$ & $\mathrm{Si}$ & Yes & - & - & 3 & Yes & 9-10 ICS & - & Yes \\
\hline Radkani and colleagues ${ }^{7}$ & $\mathrm{Si}$ & Yes & - & - & 3 & Yes & $11 \mathrm{ICS}$ & - & Yes \\
\hline Lee and colleagues ${ }^{8}$ & S & Yes & - & - & 4 & Yes & Ant $\mathrm{CP}$ angle & - & Yes \\
\hline Demir and colleagues ${ }^{9}$ & $\mathrm{~S} / \mathrm{Si}$ & Yes & - & - & 3 & Yes & 10-11 ICS & - & - \\
\hline Melfi and colleagues ${ }^{3}$ & S & No & Yes & $3-4 \mathrm{~cm}$ & 3 & - & - & - & No \\
\hline Melfi and colleagues ${ }^{10}$ & $\mathrm{Si}$ & Yes & - & - & 4 & Yes & NR & - & Yes \\
\hline Toker and colleagues ${ }^{11}$ & $\mathrm{Si}$ & No & Yes & $3 \mathrm{~cm}$ & 3 & - & 10-11th ICS & - & - \\
\hline Adams and colleagues $^{12}$ & $\mathrm{Si}$ & Yes & - & - & 4 & Yes & Ant CM & Bag & Yes \\
\hline Oh and colleagues ${ }^{13}$ & $\mathrm{Si}$ & Yes & - & - & 3 & Yes & $11 \mathrm{ICS}$ ant & - & Yes \\
\hline Augustin and colleagues ${ }^{14}$ & NR & No & Yes & NR & 3 & - & NR & - & No \\
\hline Veronesi and colleagues $^{15}$ & $\mathrm{Si}$ & No & Yes & $3 \mathrm{~cm}$ & 4 & - & 4-5 ICS & - & - \\
\hline Louie and colleagues ${ }^{16}$ & $\mathrm{Si}$ & Yes & - & - & 3 & Yes & 9-10 ICS & - & Yes \\
\hline Park and colleagues ${ }^{4}$ & $\mathrm{Si}$ & No & Yes & $4 \mathrm{~cm}$ & 3 & - & NR & - & No \\
\hline Cerfolio and colleagues ${ }^{17}$ & $\mathrm{Si}$ & Yes & - & & 4 & Yes & 9-10 ICS & Bag & Yes \\
\hline Jang and colleagues ${ }^{18}$ & $\mathrm{Si}$ & No & Yes & NR & 3 & - & $5 \mathrm{ICS}$ & - & - \\
\hline Fortes and colleagues ${ }^{19}$ & $\mathrm{Si}$ & No & Yes & $2-3 \mathrm{~cm}$ & 3 & - & 4-5 ICS & - & - \\
\hline Dylewski and colleagues $^{20}$ & $\mathrm{Si}$ & Yes & - & - & 3 & Yes & $11 \mathrm{ICS}$ & Bag & Yes \\
\hline Giulianotti and colleagues $^{21}$ & S & No & Yes & $5-6 \mathrm{~cm}$ & 3 & - & $5 \mathrm{ICS}$ & - & - \\
\hline Gharagozloo and colleagues $^{22}$ & $\mathrm{~S}$ & No & Yes & NR & 3 & - & - & - & - \\
\hline
\end{tabular}

ICS, Intercostal space; Ant, anterior mediastinum; $C P$, costophrenic; $C M$, costal margin; $N R$, not reported.

PROPOSED NOMENCLATURE SYSTEM

The primary findings in the literature search identified several different approaches to robotic thoracic operations that can be used to propose a standardized nomenclature system. There are 2 major observed differences. First, whether the operation was conducted completely portal or with the assistance of an access or utility incision; and, second, the number of robotic arms used during the operation.
A robotic portal (RP) operation is defined as any operation that use ports only (incisions that are only as large as the size of the trocars placed in them), the air in the pleural space or chest cavity does not directly communicate with the ambient air in the operating room (except around nonairtight trocars), carbon dioxide usually is insufflated in the chest and the port incision(s) is/are not generally enlarged at any time during the operation to be larger than the trocars in them except for: the removal of a specimen

TABLE 2. Robotic approaches for mediastinal diseases

\begin{tabular}{|c|c|c|c|c|c|c|c|c|}
\hline Author & System & Location & Pathology & Side & No. arms & Asst. port & Extract incision & $\mathrm{CO}_{2}$ chest \\
\hline Keijzers and colleagues $^{23}$ & $\mathrm{Si}$ & Ant & MG & $\mathrm{R}$ & 3 & - & Yes & Yes \\
\hline Huang and colleagues ${ }^{24}$ & $\mathrm{Si}$ & Ant & Thymoma & $\mathrm{L} / \mathrm{R}$ & 3 & - & Yes & Yes \\
\hline Seong and colleagues ${ }^{25}$ & $\mathrm{~S} / \mathrm{Si}$ & Ant & Mixed & $\mathrm{L} / \mathrm{R} / \mathrm{B}$ & 3 & - & Yes & Yes \\
\hline Ye and colleagues ${ }^{26}$ & NR & Ant & Thymoma & NR & 3 & - & Yes & Yes \\
\hline Marulli and colleagues ${ }^{27}$ & NR & Ant & MG & $\mathrm{L}$ & 3 & - & Yes & Yes \\
\hline Schneiter and colleagues ${ }^{28}$ & $\mathrm{Si}$ & Ant & Thymoma & $\mathrm{L} / \mathrm{R}$ & 3 & - & Yes & Yes \\
\hline Renaud and colleagues ${ }^{29}$ & $\mathrm{Si}$ & Ant & MG & $\mathrm{L}$ & 3 & - & Yes & Yes \\
\hline Cerfolio and colleagues $^{30}$ & $\mathrm{Si}$ & Post & Mixed & $\mathrm{LD}$ & 4 & - & Yes & Yes \\
\hline Mussi and colleagues ${ }^{31}$ & $\mathrm{Si}$ & Ant & Thymoma & $\mathrm{L}$ & 3 & - & Yes & Yes \\
\hline Melfi and colleagues ${ }^{32}$ & $\mathrm{Si}$ & Post & Mixed & LD & 3 & - & Yes & Yes \\
\hline Weksler and colleagues ${ }^{33}$ & $\mathrm{Si}$ & Ant & Mixed & $\mathrm{L} / \mathrm{R}$ & 3 & - & Yes & Yes \\
\hline Freeman and colleagues ${ }^{34}$ & $\mathrm{Si}$ & Ant & MG & $\mathrm{L}$ & 3 & - & Yes & Yes \\
\hline Balduyck and colleagues $^{35}$ & NR & Ant & Mixed & $\mathrm{L} / \mathrm{R}$ & 3 & 1 & Yes & Yes \\
\hline Ruckert and colleagues ${ }^{36}$ & NR & Ant & MG & $\mathrm{L}$ & 3 & - & Yes & Yes \\
\hline Wilshire and colleagues ${ }^{37}$ & $\mathrm{Si} / \mathrm{Xi}$ & Ant & Thymoma & $\mathrm{L} / \mathrm{R}$ & 3 & - & Yes & Yes \\
\hline Goldstein and colleagues ${ }^{38}$ & $\mathrm{Si}$ & Ant & MG & $\mathrm{R}$ & 3 & 1 & Yes & Yes \\
\hline Fleck and colleagues ${ }^{39}$ & NR & Ant & MG & $\mathrm{L}$ & 3 & - & Yes & Yes \\
\hline Cakar and colleagues ${ }^{40}$ & NR & Ant & MG & $\mathrm{R}$ & 3 & 1 & - & - \\
\hline Savitt and colleagues ${ }^{41}$ & NR & Ant & Mixed & $\mathrm{R}$ & 3 & - & Yes & NR \\
\hline
\end{tabular}

Ant, Anterior mediastinum; $M G$, myasthenia gravis; $R$, right chest; $L$, left chest; Mixed, thymoma, MG, cysts, other; $B$, bilateral chest; $N R$, not reported; Post, posterior mediastinum; $L D$, lateral decubitus. 
which is placed in a protective bag or the need to slightly enlarged the incision to place a stapler or a larger percutaneous instrument.

Robotic operations that include a utility incision will be defined as robotic-assisted (ie, RA) procedures. A utility incision is defined as an incision in the chest that may or may not have trocars or robotic arms placed through it which allows communication between the ambient air in the operating room and the pleural space and by virtue of its size precludes pressurization of the ipsilateral thorax by $\mathrm{CO}_{2}$ insulation. This is in contradistinction to an extraction port which enlarges a trocar incision at the end of the operation for specimen removal.

The use of these definitions as a base allows for the creation of a simple process for researchers to describe their specific robotic approach. Such as system would use the following:

First letter $=\mathrm{R}$ for robot

Second letter $=\mathrm{P}$ for portal or $\mathrm{A}$ for assist

Third letter(s) - what operation is being performed (see section to follow)

Fourth letter-the number of robotic arms used

In the case of pulmonary resection, the third letter would be designated as lobectomy (L), segmentectomy (S), or wedge resection (W). As increasingly complex cases are performed, this can be expanded to include pneumonectomy (P) and sleeve lobectomy (SL). Furthermore, a completely portal lobectomy that uses 4 arms is a RPL-4. A robotic segmentectomy that is completely portal that uses 3 arms would be RPS-3. A robotic lobectomy that uses 4 arms with a utility incision is abbreviated RAL-4.

For mediastinal diseases, the operations were all conducted without an access incision, although it is possible that some may add one in the future. In the majority of reports, 3 arms were used. A robotic portal 3-armed thymectomy would be RPT-3. The challenge with mediastinal diseases, however, is the wide variety of pathology encountered and how to use the third letter to describe the operation. One possible option is to simply describe the mediastinal compartment accessed, which includes the anterior mediastinal (ie, AM), posterior mediastinal (ie, PM), and middle mediastinum (ie, MM). As such, a 3-arm robotic resection of an esophageal leiomyoma would be a RPPM-3. For now, we suggest the use of R for robotic and $\mathrm{P}$ for portal or $\mathrm{A}$ for access incision and then the name of the operations performed. For example, the resection of an esophageal leiomyoma using a robotic portal technique would be a RP-esophageal leiomyomectomy-3.

\section{DISCUSSION}

Robotic surgery represents a new surgical frontier. Some form of computerized minimally invasive system is the likely future of all surgery. One of the largest setbacks to VATS was the lack of advantages noted from some earlier trials. In retrospect, it turned out to be that a few centers in the early trials were spreading the ribs. During the infancy of VATS, some surgeons perverted the true advantages of VATS to market themselves as VATS surgeons. Some made an incision, placed a chest retractor and spread the ribs, and used a VATS camera only to illuminate the surgical field. This type of VATS blurred some of the now known advantages of minimally invasive surgery compared with thoracotomy.

This experience suggests that definitions are needed during the infancy of new surgical techniques and this incudes robotic thoracic surgery. The main import of this consensus statement is to define terms to avoid confusion. The purpose of this manuscript is to adopt an international language that clearly defines what constitutes a robotic thoracic operation, what are the different ways to perform them, and how should they be defined to describe the current literature as well as be adaptable to the future.

Nomenclature systems are needed to define the core elements of a surgical intervention. The agreement on definitions, nomenclature, and classifications of the different types of robotic operations allows surgeons to better communicate with one another and ensure the critical and honest evaluation of the results of their specific operative techniques. However, these definitions should not be so restrictive so as to prevent the inclusion of new robotic systems, slow the development of new operative techniques, or quell surgical innovators from developing further improvements. Importantly, the meteoritic advance of robotic surgery also suggests the need to develop specialty-training programs in robotic surgery that carefully define parameters that are needed for credentialing. Credentialing is impossible until we first define exactly what we are trying to credential. The important topic of how best to train and credential, which will protect surgeons and patients alike, will requires an entire separate manuscript and will be the next project of the robotic international working group.

In conclusion, the American Association of Thoracic Surgery robotic writing group agrees that terminology and nomenclatures are needed in the infancy of robotic surgery to help prevent confusion and improve communication abroad. A definition is proposed. In addition, a simple to apply and use nomenclature system also is proposed to allow surgeons to describe their robotic approach based on the current literature. It should be implemented in all literature on robotic operations. This will allow us to all speak the same language and in so doing better evaluate and compare our results.

\section{Conflict of Interest Statement}

Dr Cerfolio is a teacher for Intuitive, C-SATS, Bovie, Ethicon, Covidien, Myriad, Community Health Services, and 
Bard Medical. Dr Farivar has a past relationship with Intuitive Surgical. Dr Onaitis discloses proctoring and Epicenter for Intuitive. Dr Park was past proctor for Intuitive Surgical, honoraria from Bard, Baxter, and Covidien. Dr Louie has a past relationship with Intuitive Surgical.

The authors acknowledge the assistance of Asem Fawzi Ghanim, MD; Ms Casilde Sesti, PhD Manager, Medical Science Liaison; and Ms Carrie Grinstead, Regional Medical Librarian. Providence Health and Services.

\section{References}

1. R BW. Mosby's Medical Dictionary. Elsevier: St Louis, MO; 2013;1986.

2. Bodner J, Wykypiel H, Greiner A, Kirchmayr W, Freund MC, Margreiter R, et al. Early experience with robot-assisted surgery for mediastinal masses. Ann Thorac Surg. 2004;78:259-65; discussion 265-6.

3. Melfi FM, Menconi GF, Mariani AM, Angeletti CA. Early experience with robotic technology for thoracoscopic surgery. Eur J Cardiothoracic Surg. 2002; 21:864-8.

4. Park BJ, Flores RM, Rusch VW. Robotic assistance for video-assisted thoracic surgical lobectomy: technique and initial results. J Thorac Cardiovasc Surg. 2006;131:54-9

5. Swanson SJ, Herndon JE, D'Amico TA, Demmy TL, McKenna RJ, Green MR, et al. Video-assisted thoracic surgery lobectomy: report of CALGB 39802-a prospective, multi-institution feasibility study. J Clin Oncol. 2007;25:4993-7.

6. Rinieri P, Peillon C, Salaun M, Mahieu J, Bubenheim M, Baste J-M. Perioperative outcomes of video- and robot-assisted segmentectomies. Asian Cardiovasc Thorac Ann. 2016;24:145-51.

7. Radkani P, Joshi D, Barot T, Williams RF. Robotic video-assisted thoracoscopic lung resection for lung tumors: a community tertiary care center experience over four years. Surg Endosc. 2015;30:619-24.

8. Lee BE, Korst RJ, Kletsman E, Rutledge JR. Transitioning from video-assisted thoracic surgical lobectomy to robotics for lung cancer: are there outcomes advantages? J Thorac Cardiovasc Surg. 2014;147:724-9.

9. Demir A, Ayalp K, Ozkan B, Kaba E, Toker A. Robotic and video-assisted thoracic surgery lung segmentectomy for malignant and benign lesions. Interact Cardiovasc Thorac Surg. 2015;20:304-9.

10. Melfi FMA, Fanucchi O, Davini F, Romano G, Lucchi M, Dini P, et al. Robotic lobectomy for lung cancer: Evolution in technique and technology. Eur J Cardiothoracic Surg. 2014;46:626-31.

11. Toker A, Özyurtkan MO, Kaba E, Ayalp K, Demirhan Ö, Uyumaz E. Robotic anatomic lung resections: the initial experience and description of learning in 102 cases. Surg Endosc. 2016;30:676-83.

12. Adams RD, Bolton WD, Stephenson JE, Henry G, Robbins ET, Sommers E. Initial multicenter community robotic lobectomy experience: comparisons to a national database. Ann Thorac Surg. 2014;97:1893-8; discussion 1899-900.

13. Oh DS, Cho I, Karamian B, DeMeester SR, Hagen JA. Early adoption of robotic pulmonary lobectomy: feasibility and initial outcomes. Am Surg. 2013;79:1075-80.

14. Augustin F, Bodner J, Maier H, Schwinghammer C, Pichler B, Lucciarini P, et al. Robotic-assisted minimally invasive vs. thoracoscopic lung lobectomy: comparison of perioperative results in a learning curve setting. Langenbecks Arch Surg. 2013;398:895-901.

15. Veronesi G, Galetta D, Maisonneuve P, Melfi F, Schmid RA, Borri A, et al. Fourarm robotic lobectomy for the treatment of early-stage lung cancer. J Thorac Cardiovasc Surg. 2010;140:19-25.

16. Louie BE, Farivar AS, Aye RW, Vallières E. Early experience with robotic lung resection results in similar operative outcomes and morbidity when compared with matched video-assisted thoracoscopic surgery cases. Ann Thorac Surg. 2012;93:1598-605.

17. Cerfolio RJ, Bryant AS, Skylizard L, Minnich DJ. Initial consecutive experience of completely portal robotic pulmonary resection with 4 arms. J Thorac Cardiovasc Surg. 2011;142:740-6.

18. Jang H-J, Lee H-S, Park SY, Zo JI. Comparison of the early robot-assisted lobectomy experience to video-assisted thoracic surgery lobectomy for lung cancer. Innovations (Phila). 2011;6:305-10.

19. Fortes DL, Tomaszek SC, Wigle DA. Early experience with robotic-assisted lung resection. Innovations. 2011;6:237-42.
20. Dylewski MR, Ohaeto AC, Pereira JF. Pulmonary resection using a total endoscopic robotic video-assisted approach. Semin Thorac Cardiovasc Surg. 2011;23:36-42.

21. Giulianotti PC, Buchs NC, Caravaglios G, Bianco FM. Robot-assisted lung resection: outcomes and technical details. Interact Cardiovasc Thorac Surg. 2010;11:388-92.

22. Gharagozloo F, Margolis M, Tempesta B, Strother E, Najam F. Robot-assisted lobectomy for early-stage lung cancer: report of 100 consecutive cases. Ann Thorac Surg. 2009;88:380-4.

23. Keijzers M, de Baets M, Hochstenbag M, Abdul-Hamid M, zur Hausen A, van der Linden M, et al. Robotic thymectomy in patients with myasthenia gravis: neurological and surgical outcomes. Eur J Cardiothoracic Surg. 2014;48:40-5.

24. Huang P, Ye B, Yang Y, Tantai JC, Zhao H. Experience with the "da Vinci" robotic system for early-stage thymomas: report of 23 cases. Thorac Cancer. 2014;5:325-9.

25. Seong YW, Kang CH, Choi J-W, Kim H-S, Jeon JH, Park IK, et al. Early clinical outcomes of robot-assisted surgery for anterior mediastinal mass: its superiority over a conventional sternotomy approach evaluated by propensity score matching. Eur J Cardiothorac Surg. 2014;45:e68-73; discussion e73.

26. Ye B, Tantai J-C, Li W, Ge X-X, Feng J, Cheng M, et al. Video-assisted thoracoscopic surgery versus robotic-assisted thoracoscopic surgery in the surgical treatment of Masaoka stage I thymoma. World J Surg Oncol. 2013;11:157.

27. Marulli G, Schiavon M, Perissinotto E, Bugana A, Di Chiara F, Rebusso A, et al. Surgical and neurologic outcomes after robotic thymectomy in 100 consecutive patients with myasthenia gravis. J Thorac Cardiovasc Surg. 2013;145:730-6.

28. Schneiter D, Tomaszek S, Kestenholz P, Hillinger S, Opitz I, Inci I, et al. Minimally invasive resection of thymomas with the da Vinci ${ }^{\circledR}$ surgical system. Eur $J$ Cardiothoracic Surg. 2013;43:288-92.

29. Renaud S, Santelmo N, Renaud M, Fleury MC, De Seze J, Tranchant C, et al. Robotic-assisted thymectomy with da Vinci II versus sternotomy in the surgical treatment of non-thymomatous myasthenia gravis: early results. Rev Neurol (Paris). 2013;169:30-6.

30. Cerfolio RJ, Bryant AS, Minnich DJ. Operative techniques in robotic thoracic surgery for inferior or posterior mediastinal pathology. J Thorac Cardiovasc Surg. 2012;143:1138-43.

31. Mussi A, Fanucchi O, Davini F, Lucchi M, Picchi A, Ambrogi MC, et al. Robotic extended thymectomy for early-stage thymomas. Eur J Cardiothoracic Surg. 2012;41:e43-6; discussion e47.

32. Melfi F, Fanucchi O, Davini F, Viti A, Lucchi M, Ambrogi MC, et al. Ten-year experience of mediastinal robotic surgery in a single referral centre. Eur $J$ Cardiothoracic Surg. 2012;41:847-51.

33. Weksler B, Tavares J, Newhook TE, Greenleaf CE, Diehl JT. Robot-assisted thymectomy is superior to transsternal thymectomy. Surg Endosc Other Interv Tech. 2012;26:261-6.

34. Freeman RK, Ascioti AJ, Van Woerkom JM, Vyverberg A, Robison RJ. Longterm follow-up after robotic thymectomy for nonthymomatous myasthenia gravis. Ann Thorac Surg. 2011;92:1018-23.

35. Balduyck B, Hendriks JM, Lauwers P, Mercelis R, Ten Broecke P, Van Schil P Quality of life after anterior mediastinal mass resection: a prospective study comparing open with robotic-assisted thoracoscopic resection. Eur J Cardiothoracic Surg. 2011;39:543-8.

36. Rückert JC, Ismail M, Swierzy M, Sobel H, Rogalla P, Meisel A, et al. Thoracoscopic thymectomy with the da Vinci robotic system for myasthenia gravis. Ann N Y Acad Sci. 2008;1132:329-35.

37. Wilshire CL, Vallières E, Shultz D, Aye RW, Farivar AS, Louie BE. Robotic resection of $3 \mathrm{~cm}$ and larger thymomas is associated with low perioperative morbidity and mortality. Innovations (Phila). 2016;11:321-6.

38. Goldstein SD, Yang SC. Assessment of robotic thymectomy using the myas thenia gravis foundation of america guidelines. Ann Thorac Surg. 2010;89: 1080-5; discussion 1085-6.

39. Fleck T, Fleck M, Müller M, Hager H, Klepetko W, Wolner E, et al. Extended videoscopic robotic thymectomy with the da Vinci telemanipulator for the treatment of myasthenia gravis: the Vienna experience. Interact Cardiovasc Thorac Surg. 2009;9:784-7.

40. Cakar F, Werner P, Augustin F, Schmid T, Wolf-Magele A, Sieb M, et al. A comparison of outcomes after robotic open extended thymectomy for myasthenia gravis. Eur J Cardiothoracic Surg. 2007;31:501-5.

41. Savitt MA, Gao G, Furnary AP, Swanson J, Gately HL, Handy JR. Application of robotic-assisted techniques to the surgical evaluation and treatment of the anterior mediastinum. Ann Thorac Surg. 2005;79:450-5; discussion 455.

Key Words: robotic, surgery technique, lung mediastinal tumor 